\title{
Near-bottom hydrodynamic effects on postlarval settlement in the American lobster Homarus americanus
}

\author{
Ashlee Lillis $^{1,2, *}$, Paul V. R. Snelgrove ${ }^{1}$ \\ ${ }^{1}$ Ocean Sciences Centre and Biology Department, Memorial University of Newfoundland, St. John's, \\ Newfoundland A1C 5S7, Canada \\ ${ }^{2}$ Present address: Department of Marine, Earth and Atmospheric Sciences, Campus Box 8208, North Carolina State \\ University, Raleigh, North Carolina 27695-8208, USA
}

\begin{abstract}
Following a planktonic larval phase, American lobster Homarus americanus postlarvae seek out appropriate habitat in which to settle and develop through a shelter-restricted juvenile phase. Previous studies have shown that lobster postlarvae exhibit strong directional swimming ability, distinct bottom-searching behaviours, and clear responses to physical and chemical cues at settlement. However, most laboratory experiments have been conducted in still water and little is known about how hydrodynamics affect lobster settlement. We conducted flume experiments with different sizes of cobble to investigate the effect of moderate flow $\left(\sim 7.5 \mathrm{~cm} \mathrm{~s}^{-1}\right.$ free stream velocity) on postlarval swimming behaviour and settlement. In $1 \mathrm{~h}$ trials, significantly more postlarvae settled in flow than in still water. Postlarvae in flow were more likely to encounter bottom substrate than postlarvae in still water. Cobble size had no significant effect on settlement. Behavioural observations indicated that postlarval behaviour is modified by flow. In contrast to still water, postlarvae in flow appeared to deliberately sink and were entrained by bottom turbulence, thereby contributing to higher substrate encounter and settlement rates. Postlarvae in flow performed significantly fewer dives and exhibited fewer bottom searching behaviours than postlarvae in still water. Bottom flow therefore affects settlement frequency by influencing encounter rates through an interaction between passive and active processes. These results suggest that lobster settlement behaviour may be affected by spatial and temporal differences in flow and should therefore be considered when examining and predicting settlement patterns.
\end{abstract}

KEY WORDS: Postlarval settlement · Habitat selection · Hydrodynamics · Behaviour · Lobster · Homarus americanus

Resale or republication not permitted without written consent of the publisher

\section{INTRODUCTION}

Understanding the structure of marine populations requires knowledge not only of the processes that affect adult life histories, but also the processes that influence variation in the arrival and settlement of planktonic larvae (Roughgarden et al. 1988, Morgan 2001, Underwood \& Keough 2001). Many marine benthic invertebrates have complex life cycles that include a planktonic larval phase that is their primary mode of dispersal. For species with a planktonic larval phase, the settlement process is a critical transition to the seafloor environment and can be a major structuring factor for benthic populations (Underwood \& Keough 2001). Because many benthic species are sessile or sedentary as juveniles and adults, larval delivery and settlement into favourable habitats may be particularly important in determining the structure of populations and recruitment into fisheries. Larval delivery and settlement in suitable nursery grounds is thought to be determined by the complex interaction between physical and behavioural processes, 
including those at the seabed-water interface (Butman 1987).

Studies on the settlement of marine invertebrate larvae of various groups such as molluscs, echinoderms, polychaetes, cnidarians, and crustaceans, have shown that these organisms can actively select habitats in response to physical, chemical, and biological cues (Crisp 1955, 1974, Crisp \& Stubbings 1957, Scheltema 1974, Pawlik 1992, Boudreau et al. 1993a, Rittschof et al. 1998, Forward et al. 2001). However, the scales at which active versus passive processes determine settlement distributions depend on the traits of a species (e.g. swimming ability, sensitivity to cues) and on the hydrodynamic conditions in the settlement environment (Scheltema 1974, Hannan 1984, Butman 1986, 1987, Butman et al. 1988, Boudreau et al. 1990, Grassle et al. 1992). Unlike many small, weakly mobile planktonic larvae, decapod postlarvae are strong swimmers, and postlarvae of the American lobster Homarus americanus are particularly capable of rapid, oriented swimming (Ennis 1986, Cobb et al. 1989b). It has been hypothesized that these characteristics allow for relatively large-scale habitat selection by lobster postlarvae (Boudreau et al. 1990).

Postlarvae begin searching for suitable bottom habitat 2 to $6 \mathrm{~d}$ following metamorphosis from larval Stage III (Cobb et al. 1989a). Lobster settlement typically occurs in the middle of the postlarval stage (Scarratt 1973); however, in the absence of a suitable substrate, postlarvae have been found to delay settlement and molting to the first juvenile stage in laboratory experiments (Botero \& Atema 1982). Postlarvae up to late premolt stages are often caught in field surveys (Cobb et al. 1989a, Harding \& Fraser 1999), evidence that postlarvae have flexibility in selecting when and where they settle (Ennis 1995). Postlarval lobsters display a range of swimming and searching behaviours and have been shown to respond to a suite of physical and chemical cues in controlled laboratory experiments (Hadley 1905, Botero \& Atema 1982, Johns \& Mann 1987, Cobb et al. 1989a, Boudreau et al. 1990, 1991, 1992, 1993a,b). Postlarvae are known to exploit a variety of substrates, but laboratory experiments have demonstrated a preference for structurally-complex substrates such as cobble, rather than sand or mud (Botero \& Atema 1982). Size of shelter substrate has been shown to correlate with body-size of juvenile and adult lobster (Cobb 1971, Wahle 1992) but a preference for a particular cobble size at settlement has not been examined. Johns \& Mann (1987) found that lobster postlarvae choose habitats with seaweed or seaweed mimics more frequently than habitats without, suggesting that macroalgae may provide additional structural complexity preferred by lobsters. Light penetration has also been identified as one of the most important substrate characteristics for lobster at settlement, and it has been suggested that a hierarchy of cues act to ultimately determine settlement location (Boudreau et al. 1990). While settlement-stage, postlarval lobsters have been shown to respond to many physical and chemical factors in isolation, the difficulty of observing the settlement process in the field has resulted in settlement studies that have been conducted almost exclusively in the laboratory and, with few exceptions, in still water.

Water flow is a ubiquitous and highly variable factor in the coastal marine environment that inevitably has a strong influence on many ecological processes. Laboratory and field studies have demonstrated a range of flow effects on settlement of benthic marine invertebrates on soft and hard bottoms (e.g. Eckman 1983, Butman et al. 1988, Mullineaux \& Butman 1991, Pawlik et al. 1991, Snelgrove et al. 1993, 1998). Abelson \& Denny (1997) review 3 levels at which water motion may influence settlement of marine propagules: (1) hydrodynamic forces may affect a settling organism's encounter rate with substrata and/or subsequent behaviours; (2) flow regime could serve as a settlement cue that induces active behaviour and determines site selection; and (3) flow may mediate the detection of settlement cues in the environment. Because lobster settlement has been investigated primarily under static flow conditions, the effect of water motion is largely unknown. Without incorporating flow regime, it is unclear how the settlement behaviours and selectivity observed in laboratory experiments might translate to field conditions. Furthermore, the tendency towards still water experiments overlooks the possibility that habitat-associated flow acts as a physical settlement cue for lobster.

Investigation of the factors that influence the settlement process of marine species is fundamental to understanding and predicting patterns of recruitment, identifying critical habitat, and managing populations. Lobsters are effectively sedentary in the first years following settlement, and appear to generally experience little post-settlement mortality (Incze \& Wahle 1991, Palma et al. 1998); lobster densities could therefore be largely determined by postlarval delivery and settlement patterns (Palma et al. 1998, 1999). Despite the ecological and economic importance of this species and the significance of early life history stages in determining recruitment success, the behaviour of postlarval lobsters is not well-known (Lawton \& Lavalli 1995, Phillips et al. 2006).

The purpose of this study was to investigate effects of water flow on postlarval lobster settlement. In a laboratory experiment to examine the effect of flow on settlement, we examined the settlement of individual lobster postlarvae of 2 age groups under either still- 
water conditions or in a moderate flow. As settlement substrate, 2 sizes of cobble were offered to test for postlarval selection of substrate size in the 2 flow regimes. Cobble was chosen for this experiment because it is a preferred settlement substrate for lobster postlarvae (Botero \& Atema 1982, Hudon 1987, Wahle \& Steneck 1991); however, because lobster postlarval preference for a particular grain size at settlement has not been fully assessed and because cobble size affects both the structural and hydrodynamic aspects of the settlement habitat, we examined 2 cobble size ranges. In a separate experiment, lobster postlarval swimming and searching behaviours were measured in response to flow, in order to further examine the active component of substrate encounter.

\section{MATERIALS AND METHODS}

Lobster larval culture. Homarus americanus postlarvae were raised at the Ocean Sciences Centre of Memorial University, Canada. During July 2007, 15 ovigerous female lobsters were collected from Notre Dame Bay, Newfoundland using standard lobster traps. Females were transported to the Ocean Sciences Centre laboratory and maintained in separate tanks under ambient light with flowing seawater at ambient surface temperature (range: 8 to $15^{\circ} \mathrm{C}$ ). The lobsters were fed a ration of squid or mussels every $3 \mathrm{~d}$. When hatching occurred, lobster larvae were carefully collected from the adult tanks using a fine mesh net. During this period, tanks were checked at least twice daily in order to ensure that larvae were collected and removed soon after hatch. Larvae of the same age (hatched within the previous 24-h period) were cultured together in static, 101 culture containers filled with filtered seawater maintained at 17 to $19^{\circ} \mathrm{C}$. Larvae were kept under artificial light (12 h light:12 h dark cycle). Initial culture

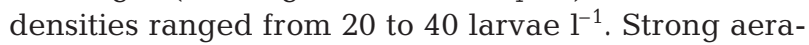
tion decreased cannibalism in the culture containers. Larvae were fed ad libitum a mixed diet of enriched frozen adult Artemia salina and live A. salina. Culture water was changed and dead larvae were removed every $2 \mathrm{~d}$. After molting to the fourth stage (postlarval stage), larvae were separated from their initial culture container and reared, using the same methods, with individuals of the same molt date in order to reduce cannibalism and to facilitate documentation of the number of days past molt (within $24 \mathrm{~h}$ ).

Settlement experiments. Settlement experiments were conducted late August to mid-September 2007. A total of 62 mid-stage ( 7 to $9 \mathrm{~d}$ past molt) and 48 latestage (12 to $16 \mathrm{~d}$ past molt) lobster postlarvae (4 to $5 \mathrm{~mm}$ carapace length) were tested individually in separate trials. Within the mid-stage age group, 31 trials were conducted in flow and 31 in still water. Within the late-stage age group, 27 trials were performed in flow and 21 in still water. The different sample sizes were dictated by limited availability of postlarvae at a specific age and the limited number of replicates possible during this time period with a single experimental apparatus. All experimental postlarvae were observed to be healthy and actively swimming. A small proportion $(15 \%)$ were missing a single cheliped (likely lost to cannibalization during communal rearing) but were included in the analysis because the 'injured' replicates were spread across treatments, and the removal of these replicates from data analysis did not produce different results.

Experiments were performed during the daylight portion of the light cycle. While little is known regarding day/night settlement patterns, postlarvae respond negatively to horizontal light (Hadley 1908) and are generally unresponsive to overhead light (Ennis 1975). Similar numbers of postlarvae are caught in the surface during daytime and nighttime surveys (Ennis 1995). Therefore, the difference between settlement in the dark versus light was not considered in this study.

Experiments were carried out in a $7 \mathrm{~m}$ long linear flume (Fig. 1A) with a $0.5 \mathrm{~m}$ wide channel and a $0.88 \mathrm{~m}$ long test section. Water depth was $10 \mathrm{~cm}$ (measured from the flush flume bottom) during all experiments. In order to create realistic benthic flow in a flume without secondary circulation induced by the sidewalls, a minimum width-to-depth ratio of 5:1 is necessary (Nowell \& Jumars 1987). Given this restriction, the flume environment is not meant to approximate the depth of the water column in which lobster postlarvae settle in the wild ( 5 to $20 \mathrm{~m}$ ), but rather to simulate the benthic flow conditions that postlarvae may encounter near bottom during settlement.

Flow is generated in the flume by an impellor that is driven by a variable-speed motor. The flume was filled with unfiltered seawater maintained between 16 and $19^{\circ} \mathrm{C}$ by a heater/chiller unit connected to a titanium heat exchange panel in the flume return pipe. To create 2 substrate choices, the test section substrate array of the flume was filled with a single layer of seawaterconditioned quarry cobble of 2 size ranges (small: $9.1 \pm$ $0.2 \mathrm{~cm}$, large: $17.2 \pm 0.2 \mathrm{~cm}$ ) on top of medium grain sand, divided on the longitudinal axis (Fig.1B). The sand in the test section sloped down from the edge of the smooth upstream bottom so that the sand between cobble pieces was $\sim 2 \mathrm{~cm}$ deeper and created a smooth transition from the acrylic flume bottom to the cobble test section. Cobbles abutted so that crevices formed between adjacent stones. Small cobble pieces protruded $\sim 3 \mathrm{~cm}$ and large pieces $\sim 5 \mathrm{~cm}$ above the sand bottom (Fig. 1C). The 2 cobble sizes offered postlarvae contrasting habitat characteristics in 2 key ways: 


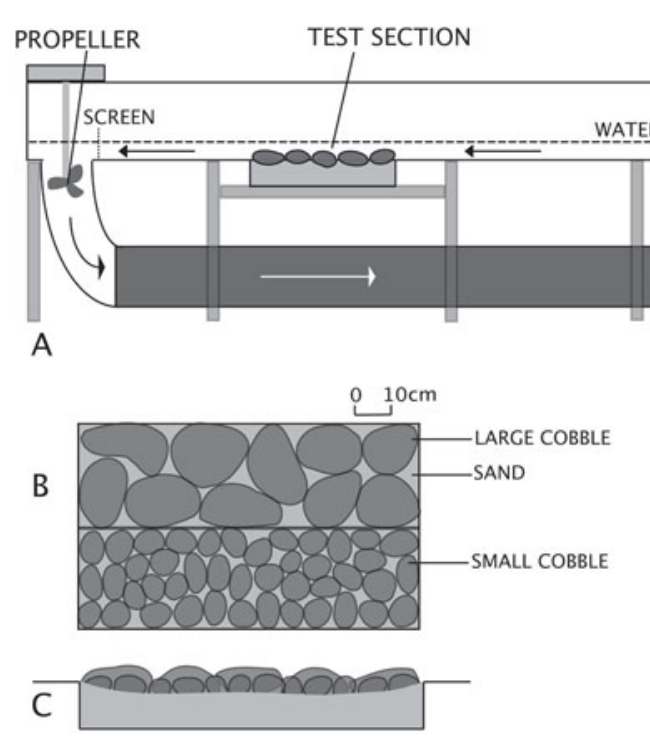

Fig. 1. Flow tank. (A) Side view of channel flume. (B) Top view of substrate arrangement in test section. (C) Side view of relative heights of substrates in test section. Location of cobble treatments were periodically switched throughout the experiment

(1) different crevice sizes in which to shelter; and (2) in flowing water, different hydrodynamic environments over the different-sized protruding structures. Every 2 to $3 \mathrm{~d}$ during the experimental period, the flume water was replaced, and the test section reconfigured to ensure that each side of the test section held each cobble treatment for half of the trials to avoid any potential cross-stream location bias.

At the onset of each trial, an individual postlarva was gently introduced at the upstream edge of the flume test section using a mesh net. Postlarvae exited the net themselves by crawling or swimming. Constant observations of location and behaviour were made for 15 min following introduction; if settlement did not occur within this time period, the postlarva was left in the flume and observed for $5 \mathrm{~min}$ periods every $15 \mathrm{~min}$. Trials were discontinued when settlement occurred or at $t=1 \mathrm{~h}$. Time to settlement and settlement substrate were recorded for settling individuals.

Because postlarvae do not become immobile at settlement, criteria to define settlement are limited. Postlarvae in this experiment were considered settled when they became sheltered under or burrowed between rocks for longer than 5 min based on observations during preliminary trials that if postlarvae did not leave the cobble within 2 to 3 min of encounter, they typically remained there for the remainder of the trial (up to $1 \mathrm{~h}$ ). Juvenile stage lobsters are thought to have high shelter fidelity post-settlement and are unlikely to re-suspend after burrowing/shelter-building (Barshaw \& Bryant-Rich 1988). Nonetheless, using a 5 min criterion, we can determine only initial settlement patterns, acknowledging that long-term settlement outcomes could differ and require additional experimental work that focuses on a longer time scale.
If the postlarva was not visible at the beginning of an observation period (i.e. had settled into cobble during non-observation), the test section was observed for the 5 min period and if the postlarva did not reappear it was scored as settled, the trial was discontinued and the postlarva was located by removing cobble pieces. If settlement occurred during unobserved periods, the time was recorded to the nearest 15 min interval. Individuals that had not settled by the end of the $1 \mathrm{~h}$ trial were scored as not settled.

Count data obtained from these experiments were analysed using the generalized linear model procedure (SAS statistical software). Response variables of (1) settlement (settled/not settled), (2) settlement substrate (small/large cobble), (3) substrate encounter during observation (encounter/no encounter), and (4) settlement following encounter (encountered and settled/encountered and did not settle), were modeled in terms of the nominal predictor variables postlarval age (mid-stage/late-stage) and flow treatment (flow/ still water). Models for these binary data used a binomial distribution and a logit link function. Effects of postlarval age and flow treatment on time to settlement were analysed using a generalized linear model procedure with a Poisson distribution and log link. Chi-square tests of model coefficients were used in the generalized linear model procedure to test which experimental variables were significant predictors of the variance in response variables. For all analyses, plots of residuals versus fitted values were used to evaluate assumptions of homogenous errors and whether the structural models adequately represented the relationships.

Flow characterization. To characterize the hydrodynamic environment in the flume during the flow trials, 

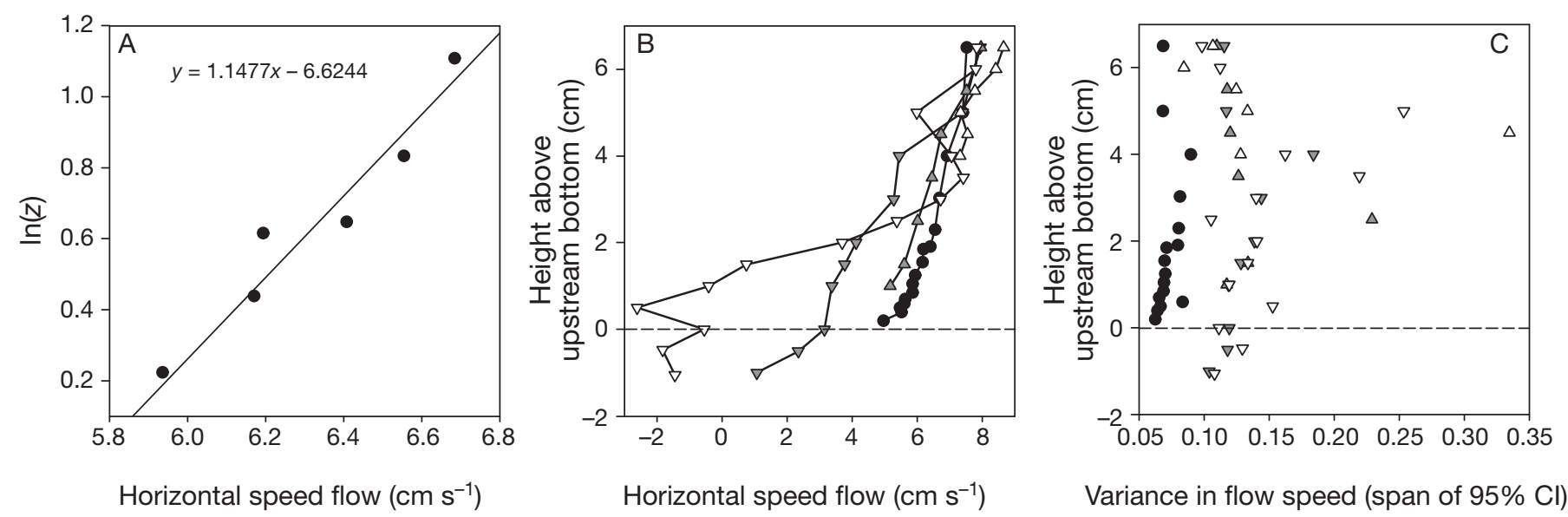

Fig. 2. (A) Semi-logarithmic plot of $\ln (z)$ vs. horizontal flow speed at $7.5 \mathrm{~cm} \mathrm{~s}^{-1}$ free stream velocity upstream of flume test section. (B) Depth profiles of horizontal flow speed upstream of the test section $(\bullet)$, above small cobble $(\triangle)$, in a small cobble crevice $(\nabla)$, above large cobble $(\Delta)$, and in a large cobble crevice $(\nabla)$. Heights are relative to the bottom upstream of the test section (dashed line); depths in test section crevices are $\sim 2 \mathrm{~cm}$ deeper than upstream bottom. (C) Profiles of turbulence (variance in horizontal flow speed in $\mathrm{cm} \mathrm{s}^{-1}$ ) upstream of and in the test section. Symbols are the same as in (B)

vertical depth profiles of velocity were measured at different locations in the flume: $0.5 \mathrm{~m}$ upstream of the test section in the middle of the channel, and above the top of a rock and a crevice for each substrate treatment mid-way along the test section (Fig. 2). The bounding surface at each location (i.e. rock surface, flume bottom) was the bottom from which height $(z)$ measurements were made. All flow measurements were performed with a Sontek $16 \mathrm{MHz}$ Microacoustic Doppler Velocimeter (ADV) connected to a positioning system to allow measurements at defined coordinates $(x, y, z)$ in the flume channel. A sampling volume of $0.75 \mathrm{~mm}^{3}$ was used and each point was sampled for $\sim 300$ s (>3000 samples per point).

All flow experiments were conducted using a moderate, smooth-turbulent flow, with a free-stream velocity of $\sim 7.5 \mathrm{~cm} \mathrm{~s}^{-1}$. This velocity is within the range of tidal flows measured during flood tide $\left(6.7 \pm 3 \mathrm{~cm} \mathrm{~s}^{-1}\right)$ at known lobster recruitment areas in the Gulf of Maine (Incze et al. 2000). Boundary shear velocity $\left(u^{*}\right)$ is a measure of the shear stress acting on a boundary and is typically used as a convenient velocity parameter to characterize near-bottom flow (Nowell \& Jumars 1984). The shear velocity upstream of the flume test section was calculated to be $0.34 \mathrm{~cm} \mathrm{~s}^{-1}$ using the log layer of the upstream velocity profile (Fig. 2A) and the formula:

$$
\ln (z)=\frac{\kappa}{u^{*}} u+\ln \left(z_{0}\right)
$$

where $\kappa$ is von Karman's constant $(=0.41), u$ is the velocity at height $z_{1}$ and $z_{0}$ is the bottom roughness parameter. This $u^{*}$ is typical of mid-range near-bottom flow in a coastal embayment (Butman 1986, Grassle et al. 1992).
Swimming behaviour experiments. We tested the swimming behaviour responses of lobster postlarvae to flow in the absence of settlement substrate during the daylight period of the light cycle. The flume was again filled to $10 \mathrm{~cm}$ depth with unfiltered 16 to $19^{\circ} \mathrm{C}$ seawater. A total of 25 postlarvae (9 to $16 \mathrm{~d}$ past molt) were used in swimming behaviour trials. In the flume, with the cobble substrate made unavailable, each postlarva was observed for $15 \mathrm{~min}$ in a moderate flow (same speed as in settlement experiments) and for $15 \mathrm{~min}$ in still water. Time spent at the surface (top $1 \mathrm{~cm}$ ), time spent at the bottom (within $1 \mathrm{~cm}$ of the flume bottom) and time spent in the water column was recorded. During each trial, 3 behaviours were characterized (adapted from Cobb et al. 1989a; Fig. 3) and enumerated: the number of full descents, partial descents (departures from the surface to mid-water, returning to the surface within $30 \mathrm{~s}$ ), and of lift-offs (departures from the bottom to mid-water, returning to the bottom within $30 \mathrm{~s}$ ). Between the 2 swimming trials, the postlarva was removed from the flume for 10 min before it was reintroduced for the alternative treatment. It is possible that experimental handling affected lobster behaviour, but every effort was made to minimize handling time and lobsters experienced consistent handling at each introduction; there was no systematic change observed in behaviour as the experiments progressed. To ensure that the sequence of treatments did not affect the individuals' responses, the order of exposure to the 2 experimental conditions was alternated among the test subjects, so that the order of trials was flow followed by still water for half of the postlarvae, and still water followed by flow for the remaining postlarvae. 


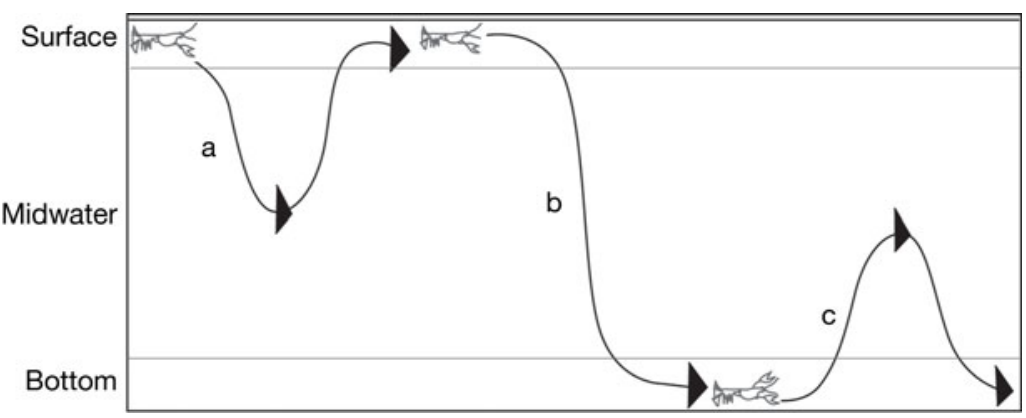

Fig. 3. Homarus americanus postlarval searching behaviours: (a) partial descent, (b) full descent (c) lift-off

Paired $t$-tests were utilized to analyze the swimming behaviour trial data. The mean number of descents (full and partial) and lift-offs performed, as well as the mean time spent by postlarvae in surface, mid, and bottom waters was compared between still-water and flow trials.

\section{RESULTS}

\section{Flow conditions}

Horizontal flow accelerated as it moved over the roughness elements in the substrate test section, reaching $\sim 8$ and $8.5 \mathrm{~cm} \mathrm{~s}^{-1}$ above the small and large cobble, respectively (Fig. 2B). Flow weakened above the bottom within crevices, and crevices in the large cobble section, where rocks protruded $\sim 4.5 \mathrm{~cm}$ above the bottom, created flow eddies with increased vertical and transverse velocities and a reverse horizontal flow (Fig. 2B). The temporal fluctuation in horizontal velocities (span of $95 \%$ confidence intervals) can be used as a measure of turbulence and was generally greater in the substrate test section compared to the upstream profile. It was also more pronounced in areas of the vertical profile over the large cobble compared to the small cobble (Fig. 2C).

\section{Settlement experiments}

Flowing seawater affected multiple aspects of postlarval lobster settlement in comparison with still water. Significantly more postlarvae settled in flow treatment trials compared to still-water trials (Fig. 4; Table 1). The effect of flow was consistent across both age classes; however, a higher proportion of late-stage postlarvae settled compared to younger individuals. In flow trials, many postlarvae were observed to quickly descend following introduction by deliberate sinking with claws and abdomen extended while they were transported by the current. When the postlarvae entered the turbulent area above the substrate section, this behaviour typically resulted in advection of the postlarva to the substrate. The postlarvae most often came into contact with the substrate within the first few minutes in flow treatments during their initial pass over the test section. Those that did not encounter and settle quickly in flow were generally observed to alternately swim upstream and drift back downstream with the current, utilizing sinking behaviour to contact bottom. In contrast, postlarvae in still-water trials most often swam actively at introduction, and later encountered substrate through repeated forward diving and/or deliberate sinking behaviour.

There was no significant preference for small or large cobble as a settlement substrate in this experiment. Although a slightly larger percentage of postlarvae settled in small cobble in flow compared to stillwater treatments (Fig. 4), this difference was not significant, and the proportion of postlarvae settling in each cobble type did not differ between the 2 age groups (Table 1).

During the first 15 min of trials, $73 \%$ of all lobsters tested encountered the substrate section. However, lobsters were significantly more likely to encounter substrate in the flow treatment than in the still-water treatment (Fig. 5; Table 1). The proportion of lobsters that encountered substrate was significantly different between the 2 age groups; in each hydro-dynamic treatment, late-stage postlarvae encountered substrate more frequently than mid-stage postlarvae (Table 1).

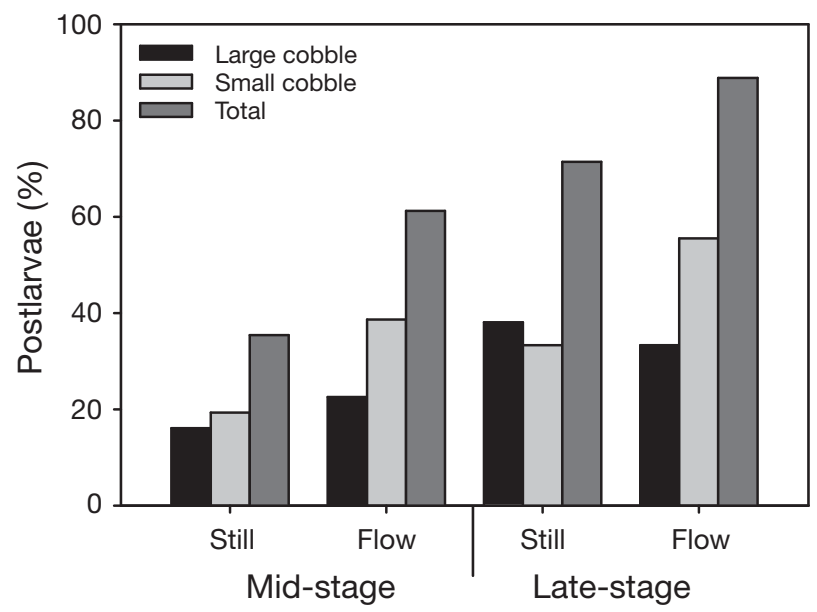

Fig. 4. Percentage of Homarus americanus postlarvae for: settling in still water and flow trials for each age class; settling within each cobble treatment; and total postlarval settlement 
Table 1. Statistics for generalized linear models of proportional settlement and encounter data. Statistical significance: ${ }^{*} \mathrm{p}<0.05$,

$$
{ }^{* *} \mathrm{p}<0.01
$$

\begin{tabular}{|lccl|}
\hline Dependent variable & Predictor & $\chi^{2}$ & \multicolumn{1}{c|}{$\mathrm{p}$} \\
\hline Settlement & Age & 12.68 & $0.0004^{* *}$ \\
(yes/no) & Flow treatment & 5.88 & $0.0153^{*}$ \\
& Interaction & 1.869 & 0.9103 \\
Settlement substrate & Age & 0.965 & 0.326 \\
(small/large) & Flow treatment & 0.114 & 0.736 \\
& Interaction & 0.080 & 0.778 \\
Substrate encounter & Age & 4.702 & $0.030^{*}$ \\
(yes/no) & Flow treatment & 7.569 & $0.006^{* *}$ \\
& Interaction & 1.869 & 0.172 \\
Encountered substrate but & Age & 6.696 & $0.010^{*}$ \\
did not settle (yes/no) & Flow treatment & 0.019 & 0.889 \\
& Interaction & 0.397 & 0.529 \\
& & & \\
\hline
\end{tabular}

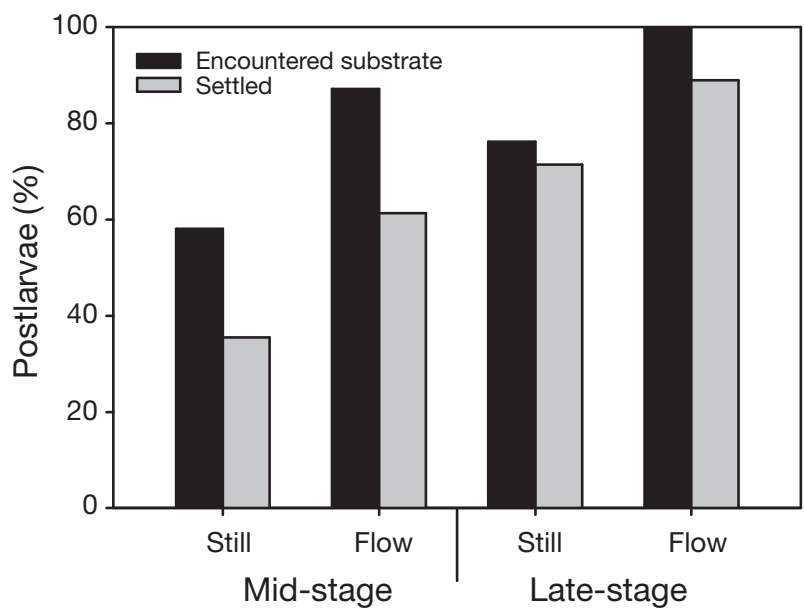

Fig. 5. Percentages of mid-stage and late-stage Homarus americanus postlarvae in still water and in flow that encountered substrate within 15 min of trial start. Bar shading = settlement outcomes of postlarvae that encountered substrate

The majority of lobsters that encountered substrate eventually settled during the trials: only 19 of 80 lobsters $(24 \%)$ that encountered the substrate within the first $15 \mathrm{~min}$ did not settle during the trial period. Of these individuals that did not settle, significantly more were mid-stage lobsters (Fig. 5; Table 1). Flow condition did not have an effect on this relationship in that lobsters of both age groups were as likely to settle after encountering substrate in flow or still water. Thus, the effect of flow was related to likelihood of encounter with the substrate rather than likelihood of settling once the encounter had occurred.

Flow and postlarval age had an interactive effect on the time to settlement (Fig. $6 ; \chi^{2}=4.69, p=0.0136$ ); therefore, each predictor was analysed separately (Table 2). No significant difference in time to settlement was found between the 2 flow treatments for either age group (Table 2). Late-stage postlarvae settled more quickly than mid-stage postlarvae in both flow and still water (Table 2; Fig. 6). In these experiments, time to settlement included 2 components: the time to encounter substrate, and the time spent in the substrate choosing or creating a shelter. The younger postlarvae generally explored more within the substrate compared to older individuals, and took more time choosing a crevice or creating a burrow in which to remain. Younger postlarvae were also often observed to make multiple contacts with the substrate, reentering the water column, whereas late-stage postlarvae typically remained in the substrate after the initial encounter. The interaction detected in the analysis is due to a difference in magnitude of the effect of age on time to settlement between flow and still water (Table 2). Flow increased the age effect, most likely by decreasing the time it took to encounter substrate, which led to quicker settlement by the late-stage postlarvae with a higher propensity to settle than mid-stage postlarvae. Individ-

Table 2. Statistical analysis of the interaction of Homarus americanus postlarval age and flow treatment on time to settlement. Statistical significance: ${ }^{*} p<0.05,{ }^{* *} p<0.01$

\begin{tabular}{|llrc|}
\hline Observations used & Predictor & $\chi^{2}$ & $\mathrm{p}$ \\
\hline Mid-stage & Flow treatment & 2.86 & 0.0909 \\
Late-stage & Flow treatment & 3.23 & 0.0721 \\
Still & Postlarval age & 4.39 & $0.0362^{*}$ \\
Flow & Postlarval age & 45.32 & $<0.0001^{* *}$ \\
\hline
\end{tabular}

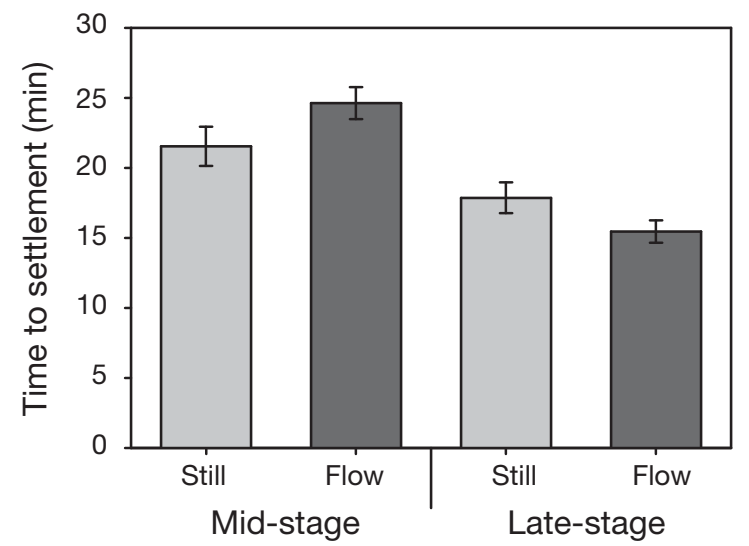

Fig. 6. Mean time to settlement $( \pm \mathrm{SE})$ for mid-stage and latestage Homarus americanus postlarvae that settled in $1 \mathrm{~h}$ still water and flow trials 


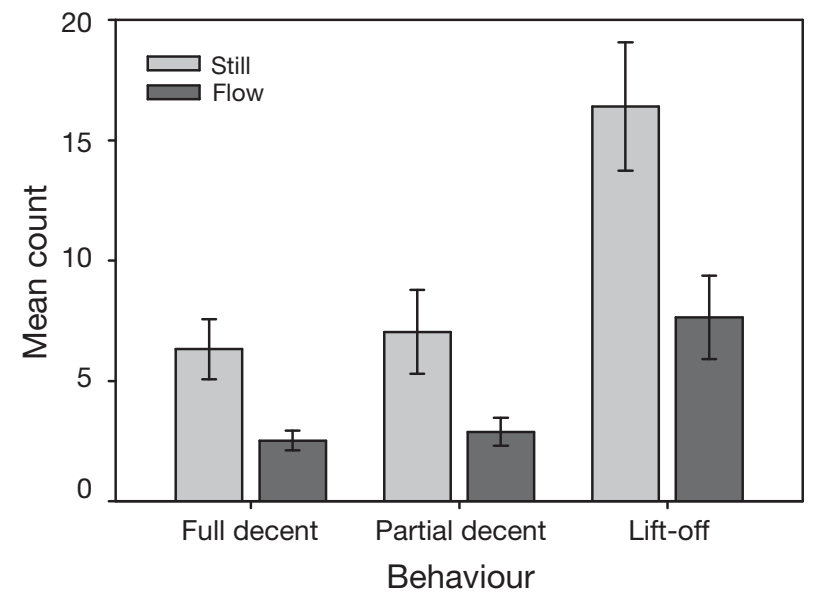

Fig. 7. Mean number $( \pm \mathrm{SE})$ of full descents, shallow descents, and lift-offs performed by Homarus americanus post-larvae in still water and in flow trials

ual variation in searching times within the substrate possibly negated any direct effect of the decreased encounter time conferred by the flow on total time to settlement.

\section{Swimming behaviour trials}

Postlarvae were more active in their searching while in still water. In still-water trials, the mean number of full descents by postlarvae was significantly greater than in flow trials (Fig. 7; $t$-test: $t=3.05, \mathrm{p}<0.01$ ). Postlarvae also performed significantly more partial descents $(t=3.32, \mathrm{p}<0.01)$ and lift-off behaviours $(t=$ 2.94, $\mathrm{p}<0.01$ ) in still water compared to flow (Fig. 7). The postlarvae actively swam against the current during flow trials, typically at speeds equal to or slightly less than the current speed. In flow, postlarvae encountered the bottom mostly through deliberate sinking behaviour, as the current transported them backwards and to the bottom, with their claws out and abdomen extended. This behaviour was in contrast to directed diving as the main mode of descent in stillwater trials. In flow, once in contact with the bottom, postlarvae often remained on and explored the surface by walking, whereas in still water, lift-offs were the preferred method of searching after initial contact.

No significant difference was found between still and flow trials in the time spent by postlarvae at the surface (Fig. 8; $t=0.672, \mathrm{p}=0.508$ ). On average, postlarvae spent more time on the bottom in flow compared to still water, but this difference was not significant $(t=1.907, \mathrm{p}=0.101)$. However, the postlarvae spent significantly more time in mid-water during stillwater trials $(t=3.861, \mathrm{p}<0.01)$ as a result of the

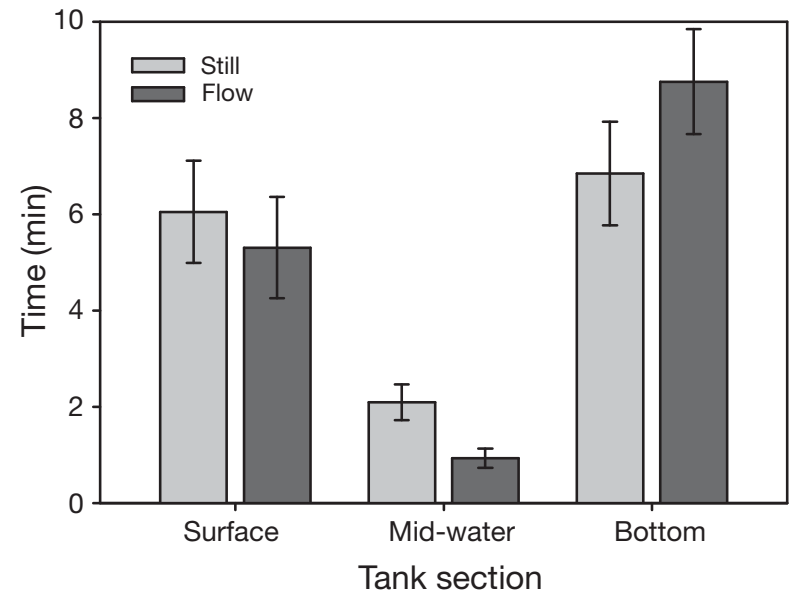

Fig. 8. Mean time $( \pm \mathrm{SE})$ spent in surface, mid-water, and bottom sections by Homarus americanus postlarvae in still water and flow trials

increase in diving and lift-off behaviours that brought them into the mid-section of the water column.

\section{DISCUSSION}

This is the first investigation to focus expressly on the role of near-bottom flow in American lobster postlarval settlement. Crustacean species such as Homarus americanus that exhibit strong swimming abilities, substrate preferences, and responsiveness to cues offer a compelling study subject to investigate the effects of hydrodynamics on larval settlement. The superior swimming capability of lobster postlarvae provides a contrast with the weaker swimming mollusc (e.g. Snelgrove et al. 1993, 1998, Boxshall 2000, Crimaldi et al. 2002), barnacle (e.g. Crisp 1955, Mullineaux \& Butman 1991, Berntsson et al. 2000) and polychaete (e.g. Butman et al. 1988, Butman \& Grassle 1992, Grassle et al. 1992, Pawlik \& Butman 1993, Snelgrove et al. 1993) larvae that have been the focus of previous studies of settlement in flow. The objective of the present study was to examine lobster settlement under realistic flow conditions and to evaluate the potential contribution of passive and active processes to lobster settlement.

The results presented here demonstrate that water flow can significantly influence lobster postlarval settlement. The observed differences in settlement and behaviour between flow and still water confirms that flow has potentially important implications for the settlement of Homarus americanus. The flow used in these experiments increased encounter rates of postlarvae with the substrate, and the probability of settlement was correspondingly higher and faster in flow compared to still-water treatments. The increased 
encounter rate and subsequent increase in settlement in flow was not simply a passive physical process, but rather one that was influenced by postlarval behavioural responses to flow. Lobster postlarvae are capable swimmers and can sustain swimming at flow speeds well above the $7.5 \mathrm{~cm} \mathrm{~s}^{-1}$ velocity used in this experiment (Ennis 1986, Cobb et al. 1989b, A. Lillis pers. obs.). However, when exposed to the flow, postlarvae modified their behaviour, deliberately sinking and subsequently coming into contact with the bottom as a result of the fluid motion, particularly in the turbulent test section. These results indicate that the behavioural mechanisms by which postlarvae reach the substratum and ultimately settle can be influenced by hydrodynamic conditions.

Settlement requires 2 events to occur: (1) substrate encounter and (2) acceptance of the encountered substrate. The latter often requires an active behaviour on the part of the larva, whereas the initial component can occur passively. Two categories of conceptual behavioural models have been used to explain active settlement of marine larvae in flow (Mullineaux \& Garland 1993, Abelson \& Denny 1997, Dobretsov \& Wahl 2008). Most commonly, larvae are thought to contact the substrate surface via advective flow, and subsequently accept or reject the surface (e.g. Butman \& Grassle 1992, Snelgrove et al. 1993). If a larva rejects the surface, it returns to the water column. Alternatively, the 'contact and explore' model suggests that certain larvae will contact a surface, and rather than make a binary accept/reject response, they will explore the substrate to locate a suitable settlement site. Neither of these models considers the influence that larval behaviour may have on substrate encounter, but rather, the 'choice' comes when larvae accept or reject a substrate. Thus, bottom flow can facilitate settlement in weaker swimmers by bringing them into contact with suitable substrate, so that much of the settlement behaviour in these species may involve vertical movement followed by passive transport (Snelgrove et al. 1993). Because larval decapods have a high swimming capacity, they may be more able to select settlement sites over larger scales than smaller, passive larvae (Luckenbach \& Orth 1992, Fernandez 1994, Hedvall et al. 1998). Rather than contact the substrate solely by advective flow, they may actively contribute to the probability of encounter with the substrate. The lobster postlarvae examined in this study demonstrated 'contact and explore' behaviour but with a clear behavioural influence on initial contact. This behavioural influence was particularly important to settlement outcome; the increased settlement in flow resulted not from differential acceptance of substrate in flow and still water, but from differences in the behaviours and subsequent substrate encounter in flow and still water.
The variation seen between the 2 age classes of Homarus americanus postlarvae in flow highlights the active behavioural contribution to substrate encounter-if the flow regime itself was the primary cause of the increased substrate encounter, we would not expect a difference between mid- and late-stage postlarvae. Moreover, flow differences associated with the 2 cobble treatments had no effect on settlement (see below). Instead, behaviour remains an important contributor to the first component of settlement in flow, and substrate encounter is higher for late-stage postlarvae. The behaviours used to encounter substrate may differ in flow versus still water, but the results presented here support and add to previous work that has demonstrated that with age, lobster postlarvae increase behaviours that lead to bottom contact (Botero \& Atema 1982, Cobb et al. 1989a, Boudreau et al. 1993b).

The behavioural differences quantified in the swimming experiment give further insight into the contrasting methods by which postlarvae may bottom-search in different flow environments. In still water, postlarvae actively dove and searched throughout the water column far more than in flow. Postlarvae in flow generally remained at the bottom once it was encountered, and walked along the bottom rather than swim. Ennis (1986) also observed a tendency for postlarvae at higher flow speeds $\left(>9 \mathrm{~cm} \mathrm{~s}^{-1}\right)$ to find the bottom and crawl more than swim, which may represent a strategy to conserve energy. This pattern suggests that in the absence of near-bottom flow and shear, postlarvae may actively search for habitat significantly more than when flow is present; however, in combination with the results of the settlement experiment, it appears that this active searching does not equal the rate of encounter attained through the utilization of near-bottom flow.

From an adaptive perspective, the postlarval settling and searching behaviours in flow appear to maximize encounter with suitable substrate while minimizing energetic requirements. In the moderate flow used in these experiments, postlarvae actively sank or dove as they were carried across the more turbulent cobblefilled test section. Despite their capacity for swimming against the flow, the postlarvae rarely exhibited searching behaviour against the current, but instead alternated between drifting with the current while actively sinking and swimming to hold position with the flow, until the bottom was encountered. In areas with even a moderate flow, such as that used here, postlarvae can utilize turbulence in order to facilitate substrate contact, and avoid the energy expenditure of repeated dives. This potential energy savings during settlement could have carry-over effects and confer an advantage to juveniles that settled through the use of flow. 
Although all postlarvae used in these experiments appeared healthy, the missing cheliped in $15 \%$ of all individuals merits comment. There was no observable difference in the swimming ability or behaviours of these individuals, and previous work found that a single missing cheliped had no effect on settlement rate or habitat selection (Boudreau et al. 1993b). The cheliped is not used as a swimming appendage in that postlarvae are propelled by pleopod beating; however, it is possible that swimming form could be affected. Nonetheless, some proportion of postlarvae is likely to sustain such appendage loss in the wild, although rates of injury for this stage in natural populations are unknown. Determination of the natural incidence of injury in postlarvae and related behavioural effects could be an important future contribution.

In field surveys, postlarvae are almost always caught in the surface layer upper meter (Hudon et al. 1986, Harding et al. 1987), a result that conflicts with the idea that postlarvae spend substantial time descending and ascending, testing bottom substrates, prior to settlement (Ennis 1995). Because postlarvae have been found to rarely cross thermal gradients, thermoclines have been suggested as a possible cue that confines them in surface waters and increases the likelihood of settlement in warmer, shallow areas (Boudreau et al. 1991, Annis 2005). The behavioural responses to flow that have been documented here suggest an additional mechanism by which postlarvae may avoid extensive active forays to the bottom in areas of inappropriate depths. Although this study examined the behaviour of postlarvae only in near-bottom flow, if the behavioural tendency to use turbulent advection in flow to minimize energy expenditure during settlement extends to postlarvae in deeper waters, then this strategy could increase the probability of substrate encounter primarily at shallow depths where appropriate settlement substrate is located. Postlarvae may limit their active movement to short descents and contact substrate if entrained by bottom turbulence. Except in instances where strong downwelling or internal waves carry postlarvae to greater depths, this effect would not be observed in deeper water.

Habitat-associated bottom flows are potentially an important component of habitat selection (Crisp 1955, Eckman 1983, Snelgrove et al. 1993, Mullineaux \& Garland 1993, Abelson \& Denny 1997). In the only other lobster settlement study that included flow as a variable, Johns \& Mann (1987) found that lobster postlarvae that settled in a 10 to $30 \mathrm{~cm} \mathrm{~s}^{-1}$ current preferred habitats with plastic seaweed mimics more than postlarvae in still water. Because flow is reduced beneath the frond structures, they suggested that lobsters seek shelter from water currents. In our study, the subtle differences in flow created by the 2 substrate sizes did not cause any significant difference in settlement. It is likely that in the moderate flow speed used, small and large cobble both provided sufficient refuge from the current. It is also possible that postlarvae do not seek shelter from moderate to low currents, but that these are ideal flow environments in which to live.

It is unclear if hydrodynamics could act as a settlement cue for lobster; although the flow promoted substrate contact, it did not affect the acceptance or rejection of that substrate in our experiment. It is possible, however, that the deliberate sinking and use of turbulence to contact substrate reflects a preference for a particular flow regime. Only 1 flow speed was tested in this experiment so additional experiments are needed to determine whether there is a preference for settlement in a particular flow regime. Nonetheless, given that flow influenced behaviour and proportion of settled larvae, these results suggest that cues associated with hydrodynamics are important for lobster settlement. Moreover, because early juvenile lobsters are generally shelter-restricted and rely on suspension feeding for the early part of their benthic life (Barshaw \& Bryant-Rich 1988, Lavalli \& Barshaw 1989, Lawton \& Lavalli 1995), there would be an expected advantage to settling in an optimal hydrodynamic environment that confers a favourable, flow-mediated supply of food and oxygen, but does not create physiological stress through heavy current or wave action. Because abiotic and biotic cues interact to determine settlement patterns, possible hydrodynamic cues should be investigated in conjunction with other known lobster settlement cues to evaluate their relative importance.

Examination of the interaction between active and passive processes during larval settlement is critical in determining the importance of the larval stage to the demography of a species (Butman \& Grassle 1992). The results of this study demonstrate the importance of flow and its effect on active settlement in lobster. This laboratory study shows that hydrodynamics may have a considerable influence on active settlement with significant implications for settlement patterns in the field. If specific flow speeds promote lobster settlement, temporal (e.g. different phases of the tide) and spatial variability in flow may be particularly influential in determining recruitment patterns. Although laboratory studies have implicated many exogenous factors in lobster habitat selection at settlement, little is known about the ability and proclivity of postlarvae to respond to these physical, chemical, and biological factors under different hydrodynamic conditions. The present experiment was not designed to examine in full the range of flow velocities and turbulence levels that postlarvae would be exposed to in the field, but rather, the results provide a starting point from which to examine the settlement of lobster under realistic 
flow conditions. Moreover, this study investigated the effects of water motion on initial settlement during daylight only, thus longer-term responses to flow, during day-night cycles, remain to be evaluated. It is clear, however, that future investigations of lobster recruitment must consider the role of hydrodynamics in determining not only large-scale larval distribution patterns, but also smaller-scale temporal and spatial settlement patterns.

Acknowledgements. We thank B. Oake, G. Brown, and the Aquaculture Research and Development Facility of Memorial University for help with logistics and D. Ings for advice on statistical approaches. P. Pepin, P. Gagnon, A. Mercier, and R. Wahle provided helpful input and comments on earlier versions of the manuscript. This work was supported by a Natural Sciences and Engineering Research Council of Canada (NSERC) Discovery Grant to P.V.R.S. and an NSERC Canada Graduate Fellowship to A.L.

\section{LITERATURE CITED}

Abelson A, Denny M (1997) Settlement of marine organisms in flow. Annu Rev Ecol Syst 28:317-339

Annis ER (2005) Temperature effects on the vertical distribution of lobster postlarvae (Homarus americanus). Limnol Oceanogr 50:1972-1982

Barshaw DE, Bryant-Rich DR (1988) A long-term study on the behavior and survival of early juvenile American lobster Homarus americanus in three naturalistic substrates: eelgrass, mud and rocks. Fish Bull 86:789-796

Berntsson KM, Jonsson PR, Lejhall M, Gatenholm P (2000) Analysis of behavioural rejection of micro-textured surfaces and implications for recruitment by the barnacle Balanus improvisus. J Exp Mar Biol Ecol 251:59-83

Botero L, Atema J (1982) Behavior and substrate selection during larval settling in the lobster Homarus americanus. J Crustac Biol 2:59-69

Boudreau B, Bourget E, Simard Y (1990) Benthic invertebrate larval response to substrate characteristics at settlement: shelter preferences of the American lobster Homarus americanus. Mar Biol 106:191-198

Boudreau B, Simard Y, Bourget E (1991) Behavioural responses of the planktonic stages of the American lobster Homarus americanus to thermal gradients, and ecological implications. Mar Ecol Prog Ser 76:13-23

Boudreau B, Simard Y, Bourget E (1992) Influence of a thermocline on vertical distribution and settlement of postlarvae of the American lobster Homarus americanus Milne-Edwards. J Exp Mar Biol Ecol 162:35-49

Boudreau B, Bourget E, Simard Y (1993a) Behavioral responses of competent lobster postlarvae to odor plumes. Mar Biol 117:63-69

Boudreau B, Bourget E, Simard Y (1993b) Effect of age, injury, and predator odors on settlement and shelter selection by lobster Homarus americanus postlarvae. Mar Ecol Prog Ser 93:119-129

Boxshall AJ (2000) The importance of flow and settlement cues to larvae of the abalone, Haliotis rufescens Swainson. J Exp Mar Biol Ecol 254:143-167

Butman CA (1986) Larval settlement of soft-sediment invertebrates: some predictions based on an analysis of nearbottom velocity profiles. In: Nihoul JCJ (ed) Marine inter- faces ecohydrodynamics, Vol 42. Elsevier, Amsterdam, p 487-513

Butman CA (1987) Larval settlement of soft-sediment invertebrates: the spatial scales of pattern explained by active habitat selection and the emerging role of hydrodynamical processes. Oceanogr Mar Biol Annu Rev 25:113-165

Butman CA, Grassle JP (1992) Active habitat selection by Capitella sp. I larvae: choice experiments in still water and flume flows. J Mar Res 50:669-715

Butman CA, Grassle JP, Webb CM (1988) Substrate choices made by marine larvae settling in still water and in a flume flow. Nature 333:771-773

> Cobb JS (1971) The shelter-related behavior of lobster, Homarus americanus. Ecology 52:108-115

Cobb JS, Wang D, Campbell DB (1989a) Timing of settlement by postlarval lobsters (Homarus americanus): field and laboratory evidence. J Crustac Biol 9:60-66

> Cobb JS, Wang D, Campbell DB, Rooney P (1989b) Speed and direction of swimming by postlarvae of the American lobster. Trans Am Fish Soc 118:82-86

Crimaldi JP, Thompson JK, Rosman JH, Lowe RJ, Koseff JR (2002) Hydrodynamics of larval settlement: the influence of turbulent stress events at potential recruitment sites. Limnol Oceanogr 47:1137-1151

Crisp DJ (1955) The behaviour of barnacle cyprids in relation to water movement over a surface. J Exp Biol 32:569-590

Crisp DJ (1974) Factors influencing the settlement of marine invertebrate larvae. In: Grant PT, Mackie AM (eds) Chemoreception in marine organisms. Academic Press, New York, NY, p 177-265

> Crisp DJ, Stubbings HG (1957) The orientation of barnacles to water currents. J Anim Ecol 26:179-196

Dobretsov S, Wahl M (2008) Larval recruitment of the blue mussel Mytilus edulis: the effect of flow and algae. J Exp Mar Biol Ecol 355:137-144

Eckman JE (1983) Hydrodynamic processes affecting benthic recruitment. Limnol Oceanogr 28:241-257

Ennis GP (1975) Behavioral responses to changes in hydrostatic pressure and light during larval development of the lobster Homarus americanus. J Fish Res Board Can 32: 2210-2213

Ennis GP (1986) Swimming ability of larval American lobsters, Homarus americanus, in flowing water. Can J Fish Aquat Sci 43:2177-2183

Ennis GP (1995) Larval and postlarval ecology. In: Factor JR (ed) Biology of the lobster Homarus americanus. Academic Press, New York, NY, p 23-46

> Fernandez M (1994) Swimming behavior of Dungeness Crab, Cancer magister Dana, megalopae in still and moving water. Estuaries 17:271-275

Forward RB, Tankersley RA, Rittschof D (2001) Cues for metamorphosis of brachyuran crabs: an overview. Am Zool 41: 1108-1122

> Grassle JP, Snelgrove PVR, Butman CA (1992) Larval habitat choice in still water and flume flows by the opportunistic bivalve Mulinia lateralis. Neth J Sea Res 30:33-44

- Hadley PB (1905) Phototropism in the larval and early adolescent stages of Homarus americanus. Science 22:675-678

> Hadley PB (1908) The behavior of the larval and adolescent stages of the American lobster (Homarus americanus). J Comp Neurol Psychol 18:199-301

Hannan CA (1984) Planktonic larvae may act like passive particles in turbulent near-bottom flows. Limnol Oceanogr 29: 1108-1116

Harding GC, Fraser AJ (1999) Application of the triacylglycerol/sterol condition index to the interpretation of larval lobster Homarus americanus distribution in close proxim- 
ity to Georges Bank, Gulf of Maine. Mar Ecol Prog Ser 186:239-254

Harding GC, Pringle JD, Vass WP, Pearre S, Smith SJ (1987) Vertical distribution and daily movements of larval lobsters Homarus americanus over Browns Bank, Nova Scotia. Mar Ecol Prog Ser 41:29-41

- Hedvall O, Moksnes PO, Pihl L (1998) Active habitat selection of megalopae and juvenile shore crabs Carcinus maenas: a laboratory study in an annular flume. Hydrobiologia 375-376:89-100

Hudon C (1987) Ecology and growth of postlarval and juvenile lobster, Homarus americanus, off Iles de la Madeleine (Quebec). Can J Fish Aquat Sci 44:1855-1869

Hudon C, Fradette P, Legendre P (1986) Horizontal and vertical distribution of larva of the lobster (Homarus americanus) around the Iles de la Madeleine, Gulf of Saint Lawrence. Can J Fish Aquat Sci 43:2164-2176

Incze LS, Wahle RA (1991) Recruitment from pelagic to early benthic phase in lobsters Homarus americanus. Mar Ecol Prog Ser 79:77-87

Incze LS, Wahle RA, Palma A (2000) Advection and settlement rates in a benthic invertebrate: recruitment to first benthic stage in Homarus americanus. ICES J Mar Sci 57: 430-437

> Johns PM, Mann KH (1987) An experimental investigation of juvenile lobster habitat preference and mortality among habitats of varying structural complexity. J Exp Mar Biol Ecol 109:275-285

Lavalli KL, Barshaw DE (1989) Post-larval American lobsters (Homarus americanus) living in burrows may be suspension feeding. Mar Behav Physiol 15:255-264

Lawton P, Lavalli KL (1995) Postlarval, juvenile, adolescent, and adult ecology. In: Factor JR (ed) Biology of the lobster Homarus americanus. Academic Press, New York, NY, p 47-88

Luckenbach MW, Orth RJ (1992) Swimming velocities and behavior of blue crab (Callinectes sapidus Rathbun) megalopae in still and flowing water. Estuaries 15: 186-192

Morgan SG (2001) The larval ecology of marine communities. In: Bertness MD, Gaines SD, Hay ME (eds) Marine community ecology. Sinauer Associates, Sunderland, MA, p 159-182

Mullineaux LS, Butman CA (1991) Initial contact, exploration and attachment of barnacle (Balanus amphitrite) cyprids settling in flow. Mar Biol 110:93-103

Mullineaux LS, Garland ED (1993) Larval recruitment in response to manipulated field flows. Mar Biol 116:667-683

Nowell ARM, Jumars PA (1984) Flow environments of aquatic benthos. Annu Rev Ecol Syst 15:303-328

Nowell ARM, Jumars PA (1987) Flumes: theoretical and experimental considerations for simulation of benthic environments. Oceanogr Mar Biol Annu Rev 25:91-112

Palma AT, Wahle RA, Steneck RS (1998) Different early post-

Editorial responsibility: Richard Osman,

Edgewater, Maryland, USA settlement strategies between American lobsters Homarus americanus and rock crabs Cancer irroratus in the Gulf of Maine. Mar Ecol Prog Ser 162:215-225

Palma AT, Steneck RS, Wilson CJ (1999) Settlement-driven, multiscale demographic patterns of large benthic decapods in the Gulf of Maine. J Exp Mar Biol Ecol 241: $107-136$

Pawlik JR (1992) Chemical ecology of the settlement of benthic marine invertebrates. Oceanogr Mar Biol Annu Rev 30:273-335

Pawlik JR, Butman CA (1993) Settlement of a marine tube worm as a function of current velocity: interacting effects of hydrodynamics and behavior. Limnol Oceanogr 38: $1730-1740$

Pawlik JR, Butman CA, Starczak VR (1991) Hydrodynamic facilitation of gregarious settlement of a reef-building tube worm. Science 251:421-424

Phillips BF, Booth JD, Cobb SJ, Jeffs AG, McWilliam P (2006) Larval and postlarval ecology. In: Phillips BF (ed) Lobsters: biology, management, aquaculture and fisheries. Blackwell Publishing, Oxford, p 231-262

Rittschof D, Forward RB, Cannon G, Welch JM and others (1998) Cues and context: larval responses to physical and chemical cues. Biofouling 12:31-44

Roughgarden J, Gaines S, Possingham H (1988) Recruitment dynamics in complex life-cycles. Science 241:1460-1466

Scarratt DJ (1973) Abundance, survival, and vertical and diurnal distribution of lobster larvae in the Northumberland Strait, 1962-1963, and their relationships with commercial stocks. J Fish Res Board Can 30:1819-1824

Scheltema RS (1974) Biological interactions determining larval settlement of marine invertebrates. Thalassia Jugosl 10:263-296

Snelgrove PVR, Butman CA, Grassle JP (1993) Hydrodynamic enhancement of larval settlement in the bivalve Mulinia lateralis (Say) and the polychaete Capitella sp. I in microdepositional environments. J Exp Mar Biol Ecol 168: 71-109

> Snelgrove PVR, Grassle JP, Butman CA (1998) Sediment choice by settling larvae of the bivalve, Spisula solidissima (Dillwyn), in flow and still water. J Exp Mar Biol Ecol 231: 171-190

Underwood AJ, Keough MJ (2001) Supply-side ecology: the nature and consequences of variations in recruitment of intertidal organisms. In: Bertness MD, Gaines SD, Hay ME (eds) Marine community ecology. Sinauer Associates, Sunderland, MA, p 159-182

> Wahle RA (1992) Substratum constraints on body size and the behavioural scope of shelter use in the American lobster. J Exp Mar Biol Ecol 159:59-75

Wahle RA, Steneck RS (1991) Recruitment habitats and nursery grounds of the American lobster Homarus americanus: a demographic bottleneck? Mar Ecol Prog Ser 69: 231-243

Submitted: July 1, 2009; Accepted: November 10, 2009 Proofs received from author(s): February 11, 2010 